\title{
Metabolic Syndrome Is an Independent Risk Factor for Acquired Premature Ejaculation
}

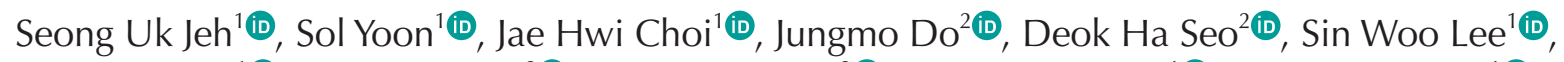 \\ See Min Choi ${ }^{1}$, Chunwoo Lee ${ }^{2}$, Sung Chul Kam²(D), Jeong Seok Hwa ${ }^{1}$, Ky Hyun Chung ${ }^{1}$, \\ Ho Won Kang ${ }^{3}$ (i), Jae Seog Hyun ${ }^{1}$ (i) \\ ${ }^{1}$ Department of Urology, Gyeongsang National University Hospital, Gyeongsang National University School of Medicine, Jinju, \\ ${ }^{2}$ Department of Urology, Gyeongsang National University Changwon Hospital, Changwon, ${ }^{3}$ Department of Urology, Chungbuk National \\ University College of Medicine, Cheongju, Korea
}

\begin{abstract}
Purpose: To determine the role of metabolic syndrome (MetS) as a risk factor for acquired premature ejaculation (PE) after considering the various risk factors, such as lower urinary tract symptoms, erectile dysfunction, hypogonadism, and prostatitis. Materials and Methods: From January 2012 to January 2017, records of 1,029 men were analyzed. We performed multivariate analysis to identify risk factors for PE, including the covariate of age, marital status, International Prostate Symptom Score, International Index of Erectile Function (IIEF) score, National Institutes of Health-Chronic Prostatitis Symptom Index (NIH-CPSI) score, serum testosterone levels, and all components of MetS. Acquired PE was defined as self-reported intravaginal ejaculation latency time $\leq 3$ minutes, and MetS was diagnosed using the modified National Cholesterol Education Program Adult Treatment Panel III criteria.

Results: Of 1,029 men, 74 subjects (7.2\%) had acquired PE and $111(10.8 \%)$ had MetS. Multivariate analysis showed that the IIEF overall satisfaction score (odds ratio $[\mathrm{OR}]=0.67, \mathrm{p}<0.001$ ), $\mathrm{NIH}-\mathrm{CPSI}$ pain score $(\mathrm{OR}=1.07, \mathrm{p}=0.035)$, NIH-CPSI voiding score $(O R=1.17, p=0.032)$, and presence of MetS $(O R=2.20, p=0.022)$ were significantly correlated with the prevalence of acquired PE. In addition, the Male Sexual Health Questionnaire for Ejaculatory Dysfunction scores and ejaculation anxiety scores progressively decreased as the number of components of MetS increased.

Conclusions: MetS may be an independent predisposing factor for the development of acquired PE. Effective prevention and treatment of MetS could also be important for the prevention and treatment of acquired PE.
\end{abstract}

Keywords: Metabolic syndrome; Obesity; Premature ejaculation; Risk factors; Sexual dysfunctions; Type 2 diabetes

This is an Open Access article distributed under the terms of the Creative Commons Attribution Non-Commercial License (http://creativecommons.org/licenses/by-nc/4.0) which permits unrestricted non-commercial use, distribution, and reproduction in any medium, provided the original work is properly cited.

\section{INTRODUCTION}

Premature ejaculation (PE) is the most common male sexual dysfunction, present in about $14.0 \%$ to $19.5 \%$ of all adult men [1,2]. In 2014, the International Society for Sexual Medicine (ISSM) defined acquired PE as characterized by a the development of a clinically significant and bothersome reduction in ejaculation

Received: Jul 16, 2018 Revised: Oct 10, 2018 Accepted: Nov 1, 2018 Published online Dec 11, 2018

Correspondence to: Jae Seog Hyun iD https://orcid.org/0000-0002-8820-4117

Department of Urology, Gyeongsang National University Hospital, Gyeongsang National University School of Medicine, 79 Gangnam-ro, Jinju 52727, Korea.

Tel: +82-55-750-8195, Fax: +82-55-757-4503, E-mail: hyunjs@gnu.ac.kr 
latency time, often to about 3 minutes or less, the inability to delay ejaculation on all or nearly all vaginal penetrations, and the presence of negative personal consequences, such as distress, bother, frustration and/ or the avoidance of sexual intimacy [3]. PE affects not only the patient but also induces considerable emotional and sexual distress in the patient's partner; in severe cases, PE can cause secondary infertility. PE has a multifactorial pathogenesis involving a variety of organic and psychological factors. Previous studies have suggested a functional imbalance of serotonin receptors as one of the most notable organic causes of PE, popularizing the use of several selective serotonin reuptake inhibitors (SSRIs) as treatment. Several studies have also reported that age, lower urinary tract symptoms (LUTS), erectile dysfunction, prostatitis, and hypogonadism contribute to the pathogenesis of PE [4-7].

Metabolic syndrome (MetS) induces impairment in vascular endothelial function and may affect blood circulation to the penis as well as the formation and secretion of nitrogen oxide, a critical component in smooth muscle expansion in the corpus cavernosum [810]. Many researchers have examined the association between MetS and erectile dysfunction and recently reached a consensus that MetS is an independent factor for erectile dysfunction [11]. MetS induces not only erectile dysfunction but also may influence the onset of PE and other ejaculatory dysfunctions because it alters serotonergic function and induces psychological changes such as depression [12-16].

Although a recent study has reported a relationship between MetS and PE, the study did not consider the potential other risk factors, such as LUTS, erectile dysfunction, and prostatitis, thus limiting the role of MetS as an independent risk factor [17]. Therefore, we investigated the role of MetS as an independent risk factor for acquired PE after considering the various risk factors, such as LUTS, erectile dysfunction, hypogonadism, and prostatitis. Furthermore, this study presents a multivariate analysis factoring in various comorbidities as well as the effects of age, LUTS, erectile dysfunction, prostatitis, and hypogonadism, which could influence the presentation of PE.

\section{MATERIALS AND METHODS}

\section{Study population}

A total of 1,337 men who visited the male health screening center of Gyeongsang National University Hospital between January 2012 and January 2017 were assessed. Men with hyperthyroidism (n=19) or psychological disorders $(n=6)$ who had undergone prostate surgery $(n=27)$ or who were taking medications including SSRIs $(n=6)$, testosterone $(n=9), \alpha$ blockers $(n=197)$, 5 - $\alpha$ reductase inhibitors $(n=94)$, or phosphodiesterase (PDE)-5 inhibitors $(n=37)$ were excluded. Those with lifelong PE $(n=72)$ who had PE symptoms since their first sexual intercourse were also excluded. Finally, 1,029 patients (ages $27-70$ years) were eligible.

\section{Ethics statement}

The present study protocol was reviewed and approved by the Institutional Review Board (IRB) of Gyeongsang National University Hospital (IRB No. 2017-03-015). Informed consent was waived by the IRB.

\section{Measurement and definition of parameters}

Routine laboratory and hormonal tests were performed between 08:00 AM and 9:00 AM in a fasting state. Waist circumference (WC) was measured just above the iliac crest at the level of the umbilicus using a standard tape measure with the patient standing. The diagnosis of MetS was made according to the most recent consensus report of the National Cholesterol Education Program Adult Treatment Panel III (NCEP ATP III) [18], which defined MetS as the simultaneous occurrence of at least 3 of the following 5 risk factors: abdominal obesity (WC greater than $90 \mathrm{~cm}$ or body mass index [BMI] greater than $25 \mathrm{~kg} / \mathrm{m}^{2}$ ), blood pressure $\geq 130 / 85 \mathrm{mmHg}$ (or current use of antihypertensive medication), fasting blood glucose $\geq 110 \mathrm{mg} / \mathrm{dL}$ (or current use of oral diabetes medication or insulin), triglyceride $\geq 150 \mathrm{mg} / \mathrm{dL}$, and high-density lipoproteincholesterol $<40 \mathrm{mg} / \mathrm{dL}$. We modified the definition of central obesity according to a new definition from the Western Pacific Regional Office of the World Health Organization instead of using the NCEP ATP III criterion of a WC greater than $102 \mathrm{~cm}$ [19]. Patients were asked to complete the International Prostate Symptom Score (IPSS) questionnaire and the National Institutes of Health-Chronic Prostatitis Symptom Index (NIHCPSI) to determine the severity of LUTS and chronic prostatitis (CP). The IPSS is the sum of scores on an 8-item questionnaire, ranging from 0-35; severity was categorized as mild (0-7), moderate (8-19), or severe (20-35). The NIH-CPSI is a 13-item questionnaire for 
the assessment of symptom severity in men with $\mathrm{CP} /$ chronic pelvic pain syndrome. For each item, score ranges are $0-1$ ( 6 items), $0-3$ ( 2 items), $0-5$ ( 3 items), $0-6$ (1 item), and 0-10 (1 item). Patients were also assessed based on the International Index of Erectile Function (IIEF)-15 and Male Sexual Health Questionnaire for Ejaculatory Dysfunction (MSHQ-EjD) scores for sexual function. The IIEF-15 is a widely used, multidimensional self-report questionnaire that assesses 5 domains of male sexual function, including erectile function, orgasmic function, sexual desire, intercourse satisfaction, and overall satisfaction (OS). The MSHQ-EjD is a shortened version of the MSHQ that is designed to assess ejaculatory dysfunction. A testosterone level $<3.5$ $\mathrm{ng} / \mathrm{mL}$ was defined as hypogonadism.

The incidence of PE was assessed with the patient self-reporting intravaginal ejaculation latency time (IELT) that included the following responses: within about 3 minutes or longer than 3 minutes. Acquired $\mathrm{PE}$ was defined as ejaculation within about 3 minutes based on the PE guidelines of the ISSM [20]. Additionally, ejaculatory disorder anxiety was assessed with the question (non-validated), "In the last month, how much anxiety did you feel about ejaculation during intercourse?" Answers were classified as 1=extreme, 2=quite a bit, $3=$ moderate, $4=\mathrm{a}$ little, and $5=$ none.

\section{Statistical analyses}

Data were expressed as mean \pm standard deviation unless otherwise specified. Group differences of baseline characteristics were determined using independent t-tests for continuous variables and the chi-squared test for categorical variables. The odds ratios (ORs) and $95 \%$ confidence intervals were determined to evaluate the relationships between PE and risk factors including MetS from multivariate logistic regression models. All analyses were performed using IBM SPSS ver. 21 (IBM Co., Armonk, NY, USA). The $\mathrm{p}<0.05$ was defined as having statistical significance.

\section{RESULTS}

\section{Patient characteristics}

Among 1,029 men, 74 subjects (7.2\%) had acquired PE (IELT $\leq 3 \mathrm{~min}$ ) and 111 (10.8\%) had MetS. The mean ages of the acquired $\mathrm{PE}$ and control groups were $48.64 \pm 8.79$ years and $48.38 \pm 7.47$ years, respectively, with no significant difference between the groups. Compared to the non-PE group, patients with PE had an increased prevalence of MetS and significant differences in total IPSS and all NIH-CPSI subdomains ( $p=0.019$ and $\mathrm{p}<0.001$, respectively; Table 1). Patients with PE showed

Table 1. Demographics and laboratory findings of subjects according to the presence of acquired premature ejaculation

\begin{tabular}{|c|c|c|c|}
\hline Characteristic & $\begin{array}{l}\text { Acquired PE } \\
\quad(n=74)\end{array}$ & $\begin{array}{l}\text { Non-PE } \\
(n=955)\end{array}$ & p-value \\
\hline Age (yr) & $48.64 \pm 8.79$ & $48.38 \pm 7.47$ & 0.782 \\
\hline Marital status & & & 0.006 \\
\hline Married & $62(83.8)$ & $898(94.0)$ & \\
\hline Single & $7(9.5)$ & $38(4.0)$ & \\
\hline Separate or divorced & $5(6.8)$ & $19(2.0)$ & \\
\hline \multicolumn{4}{|l|}{ Comorbid conditions } \\
\hline HTN & $16(21.6)$ & $218(22.8)$ & 0.688 \\
\hline $\mathrm{DM}$ & $7(9.5)$ & $85(8.9)$ & 0.871 \\
\hline IPSS & $9.66 \pm 4.93$ & $4.95 \pm 2.73$ & $<0.001$ \\
\hline \multicolumn{4}{|l|}{ IIEF } \\
\hline EF subscore & $17.65 \pm 9.20$ & $23.86 \pm 6.89$ & $<0.001$ \\
\hline OF subscore & $5.95 \pm 3.46$ & $8.05 \pm 2.62$ & $<0.001$ \\
\hline SD subscore & $5.57 \pm 2.07$ & $6.92 \pm 1.87$ & $<0.001$ \\
\hline IS subscore & $5.92 \pm 3.64$ & $9.12 \pm 3.27$ & $<0.001$ \\
\hline OS subscore & $5.04 \pm 2.05$ & $7.09 \pm 1.77$ & $<0.001$ \\
\hline MSHQ-EjD & $23.96 \pm 7.50$ & $28.33 \pm 4.75$ & $<0.001$ \\
\hline PE anxiety score & $4.23 \pm 1.04$ & $4.59 \pm 0.73$ & $<0.001$ \\
\hline \multicolumn{4}{|l|}{$\mathrm{NIH}-\mathrm{CPSI}$} \\
\hline Pain subscore & $3.72 \pm 4.63$ & $1.96 \pm 3.27$ & $<0.001$ \\
\hline Voiding subscore & $3.81 \pm 3.04$ & $2.27 \pm 2.24$ & $<0.001$ \\
\hline QoL subscore & $3.86 \pm 2.06$ & $3.06 \pm 1.90$ & $<0.001$ \\
\hline \multicolumn{4}{|l|}{ Metabolic characteristics } \\
\hline $\begin{array}{l}\text { Waist circumference } \\
(\mathrm{cm})\end{array}$ & $88.08 \pm 10.31$ & $87.49 \pm 10.87$ & 0.653 \\
\hline $\begin{array}{l}\text { Fasting blood glucose } \\
(\mathrm{mg} / \mathrm{dL})\end{array}$ & $92.59 \pm 18.89$ & $92.79 \pm 20.42$ & 0.937 \\
\hline $\mathrm{HDL}(\mathrm{mg} / \mathrm{dL})$ & $52.57 \pm 14.13$ & $52.21 \pm 13.35$ & 0.824 \\
\hline TG (mg/dL) & $151.05 \pm 152.84$ & $138.30 \pm 91.64$ & 0.278 \\
\hline Systolic BP (mmHg) & $123.76 \pm 12.16$ & $125.05 \pm 14.57$ & 0.456 \\
\hline Diastolic BP (mmHg) & $81.15 \pm 9.28$ & $80.79 \pm 11.09$ & 0.786 \\
\hline Metabolic syndrome (\%) & $14(18.9)$ & $97(10.2)$ & 0.019 \\
\hline $\mathrm{BMI}\left(\mathrm{kg} / \mathrm{m}^{2}\right)$ & $24.51 \pm 2.84$ & $24.44 \pm 2.83$ & 0.851 \\
\hline Hypogonadism & 14 (18.9) & $179(18.7)$ & 0.970 \\
\hline Testosterone (ng/mL) & $5.08 \pm 1.74$ & $5.03 \pm 1.68$ & 0.833 \\
\hline
\end{tabular}

Values are presented as mean \pm standard deviation or number (\%). PE: premature ejaculation, HTN: hypertension, DM: diabetes mellitus, IPSS: International Prostate Symptom Score, IIEF: International Index of Erectile Function, EF: erectile function, OF: orgasmic function, SD: sexual desire, IS: intercourse satisfaction, OS: overall satisfaction, MSHQ-EjD: Male Sexual Health Questionnaire for Ejaculatory Dysfunction, NIH-CPSI: National Institutes of Health Chronic Prostatitis Symptom Index, QoL: quality of life, HDL: high-density lipoprotein, TG: triglyceride, BP: blood pressure, BMI: body mass index. 
significantly lower IIEF subdomain, PE anxiety, and MSHQ-EjD scores $(p<0.001, p<0.001$, and $p<0.001$, respectively). In addition, there was a significant difference between the two groups in marital status $(p=0.006)$, with a greater proportion of married men in the control group (83.8\% vs. $94.0 \%)$ and more single men in the acquired PE group (9.5\% vs. 4.0\%).

\section{Univariate and multivariate analysis for premature ejaculation}

To determine the correlations among acquired PE, MetS, and other conditions, a logistic regression analysis was performed including the covariates of age, total
IPSS, IIEF subdomains, NIH-CPSI subdomains, MetS, BMI, hypogonadism. Univariate analysis demonstrated that LUTS severity, all NIH-CPSI subdomains and MetS were positively correlated with the prevalence of acquired $\mathrm{PE}(\mathrm{p}=0.004, \mathrm{p}<0.001$, and $\mathrm{p}=0.022$, respectively), while the IIEF subdomains were negatively correlated with acquired PE ( $<<0.001$; Table 2). After adjusting for the relevant factors, which were significant in univariate analysis, IIEF OS score (OR=0.67, $\mathrm{p}<0.001)$, CPSI pain score $(\mathrm{OR}=1.07, \mathrm{p}=0.035)$, CPSI voiding score $(\mathrm{OR}=1.17, \mathrm{p}=0.032)$, and MetS $(\mathrm{OR}=2.20, \mathrm{p}=0.022)$ were significantly associated with the prevalence of acquired PE (Table 2). In particular, the presence of MetS

Table 2. Univariate and multivariate logistic regression analysis of risk factors for acquired premature ejaculation

\begin{tabular}{|c|c|c|c|c|c|c|}
\hline \multirow{2}{*}{ Variable } & \multicolumn{3}{|c|}{ Univariate analysis } & \multicolumn{3}{|c|}{ Multivariate analysis $^{\mathrm{a}}$} \\
\hline & OR & $(95 \% \mathrm{Cl})$ & $p$-value & OR & $(95 \% \mathrm{Cl})$ & $\mathrm{p}$-value \\
\hline Age & 1.00 & $(0.97-1.04)$ & 0.782 & & & \\
\hline IPSS & & & $<0.001$ & & & 0.443 \\
\hline Mild & 1 & & & 1 & (Reference) & \\
\hline Moderate & 1.72 & $(0.99-3.00)$ & 0.055 & 0.75 & $(0.37-1.52)$ & 0.424 \\
\hline Severe & 4.85 & $(2.51-9.35)$ & $<0.001$ & 1.11 & $(0.37-3.38)$ & 0.853 \\
\hline \multicolumn{7}{|l|}{ IIEF } \\
\hline EF subscore & 0.92 & $(0.89-0.94)$ & $<0.001$ & 1.01 & $(0.95-1.07)$ & 0.805 \\
\hline OF subscore & 0.81 & $(0.76-0.87)$ & $<0.001$ & 1.12 & $(0.97-1.31)$ & 0.130 \\
\hline SD subscore & 0.71 & $(0.62-0.80)$ & $<0.001$ & 0.97 & $(0.82-1.15)$ & 0.748 \\
\hline IS subscore & 0.80 & $(0.76-0.85)$ & $<0.001$ & 0.86 & $(0.74-1.01)$ & 0.064 \\
\hline OS subscore & 0.61 & $(0.54-0.69)$ & $<0.001$ & 0.67 & $(0.53-0.83)$ & $<0.001$ \\
\hline \multicolumn{7}{|l|}{ NIH-CPSI } \\
\hline Pain subscore & 1.12 & $(1.06-1.18)$ & $<0.001$ & 1.07 & $(1.01-1.15)$ & 0.035 \\
\hline Voiding subscore & 1.28 & $(1.15-1.36)$ & $<0.001$ & 1.17 & $(1.01-1.36)$ & 0.032 \\
\hline QoL subscore & 1.24 & $(1.10-1.40)$ & $<0.001$ & 0.90 & $(0.75-1.09)$ & 0.271 \\
\hline \multicolumn{7}{|c|}{ Metabolic characteristic } \\
\hline Abnormal WC & 1.16 & $(0.71-2.22)$ & 0.101 & & & \\
\hline Abnormal BP & 0.91 & $(0.56-1.46)$ & 0.688 & & & \\
\hline Abnormal FBG & 1.07 & $(0.48-2.40)$ & 0.871 & & & \\
\hline Abnormal HDL & 1.50 & $(0.85-2.66)$ & 0.159 & & & \\
\hline Abnormal TG & 1.02 & $(0.62-1.70)$ & 0.930 & & & \\
\hline \multicolumn{7}{|l|}{ Metabolic syndrome } \\
\hline Absent & 1 & & & 1 & (Reference) & \\
\hline Present & 2.06 & $(1.11-3.83)$ & 0.022 & 2.20 & $(1.12-4.31)$ & 0.022 \\
\hline BMI & 0.85 & $(0.93-1.10)$ & 0.851 & & & \\
\hline \multicolumn{7}{|l|}{ Hypogonadism } \\
\hline Absent & 1 & & & & & \\
\hline Present & 0.99 & $(0.54-1.81)$ & 0.970 & & & \\
\hline
\end{tabular}

OR: odds ratio, Cl: confidence interval, IPSS: International Prostate Symptom Score, IIEF: International Index of Erectile Function, EF: erectile function, OF: orgasmic function, SD: sexual desire, IS: intercourse satisfaction, OS: overall satisfaction, NIH-CPSI: National Institutes of Health Chronic Prostatitis Symptom Index, QoL: quality of life, WC: waist circumference, BP: blood pressure, FBG: fasting blood glucose, HDL: high-density lipoprotein, TG: triglyceride, BMl: body mass index.

${ }^{a}$ Enter conditional method. 


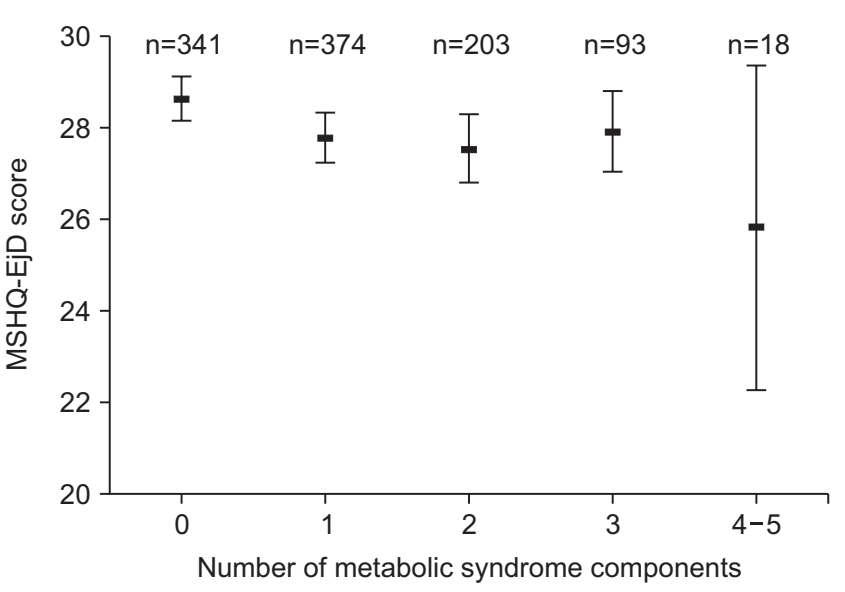

Fig. 1. The relationship between the number of metabolic syndrome components and the Male Sexual Health Questionnaire for Ejaculatory Dysfunction (MSHQ-EjD) score (mean and 95\% confidence interval).

increased the risk of acquired PE up to 2.2-fold.

\section{Metabolic syndrome and other ejaculatory dysfunction}

The MSHQ-EjD score progressively decreased as the number of components of MetS increased (ANOVA test, $\mathrm{p}=0.027$; Fig. 1). Furthermore, the ejaculation anxiety score significantly decreased as the number of MetS risk factors increased (ANOVA test, $p=0.001$; Fig. 2). After Bonferroni post hoc analysis, the mean ejaculation anxiety scores in patients with 4 or 5 MetS risk factors were significantly lower than in patients with no risk factors $(\mathrm{p}=0.001)$.

\section{DISCUSSION}

The aim of the present study was to investigate the association between acquired $\mathrm{PE}$ and various challenging factors that may affect ejaculatory function, such as age, LUTS, erectile dysfunction, prostatitis-like symptoms, testosterone, and MetS. The findings indicated that patients with MetS had a 2.2 times higher risk of acquired PE than controls. In addition, an increasing number of MetS components were associated with lower MSHQ-EjD and ejaculation anxiety scores, indicating that MetS may be associated with not only PE but also other ejaculatory dysfunction. Consistent with our results, a recent study by Bolat et al [17] showed that MetS and its component risk factors are significantly associated with acquired $\mathrm{PE}$.

The underlying mechanism by which MetS contrib-

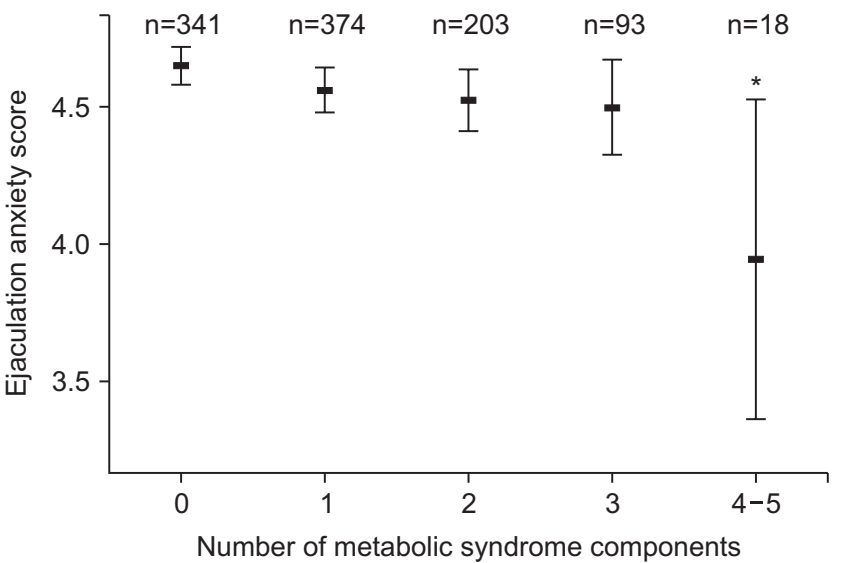

Fig. 2. The relationship between the number of metabolic syndrome components and the ejaculation anxiety score (mean and $95 \%$ confidence interval). ${ }^{*} \mathrm{p}<0.05$ vs. 0 metabolic syndrome components.

utes to the occurrence of PE has not been elucidated, but there are some hypotheses. First, MetS may induce psychological changes such as depression, which may precipitate or maintain PE. Previous studies have shown evidence of a bidirectional association between depression and MetS [12,13]. One of the largest studies of 1,598 patients with a risk of cardiovascular disease noted a positive association between depression and MetS [12]. In another study, the number of MetS components at baseline was significantly associated with the development of depression in subsequent years [21]. Second, MetS can influence the etiology of PE by inducing changes in serotonergic receptor function, which is the primary organic cause of PE [14]. Rosmond et al [15] examined 248 Swedish subjects to study the potential impact of 5-HT2A-1438G/A promoter polymorphism on obesity and found that abnormal production of the 5-HT2A gene can lead to obesity. In addition, Muldoon et al [16] reported that MetS and physical inactivity could impair central nervous system serotonergic responsivity by measuring prolactin responses induced by serotonin-releasing agents in 270 subjects with cardiovascular risk factors. Finally, MetS induced tissue inflammation such as prostatitis may contribute to the occurrence of PE. In general, the association of obesity and chronic low-grade inflammation has been evident for several years [22]. Recently, prostatic inflammation/infections have been reported to be associated with the prevalence of PE [6], and effective treatment of prostatitis improves IELT and ejaculatory control [23]. Such associations are consistent with the findings of the present study. The risk of acquired 
PE statistically significantly increased with NIHCPSI pain and voiding subdomain scores in this study $(\mathrm{OR}=1.07, \mathrm{p}=0.035$ and $\mathrm{OR}=1.17, \mathrm{p}=0.032)$. However, it might be difficult to derive clinical implications from a study with a low OR, and more research will be needed in the future.

A few epidemiologic studies have reported that patients with erectile dysfunction have high susceptibility to PE [5]. Through univariate analysis, we also found a significant association between acquired $\mathrm{PE}$ and all subdomains of IIEF. After adjustment for the relevant factors, however, only the OS subdomain was significantly associated with acquired PE. This suggests that acquired PE may be partially associated with erectile function. McMahon et al [24] conducted an experiment on patients diagnosed with $\mathrm{PE}$ and found that an 8-week administration of sildenafil did not produce significant improvement in PE but improved overall sexual satisfaction and the perception of ejaculatory control and reduced the refractory time before a second erection. However, Lee et al [25] reported that combined therapy of dapoxetine and mirodenafil in patients with lifelong PE improved IELT and overall sexual act time compared with that of dapoxetine alone. While it is evident that PE partially or closely linked to erectile dysfunction, PDE-5 inhibitors as firstline treatment in $\mathrm{PE}$ patients without erectile dysfunction are still controversial.

In this study, we also analyzed the association between acquired PE and age, severity of LUTS, and hypogonadism, but did not find a statistically significant association. In the literature, some studies have found age to be a predisposing factor for PE [26]. However, according to a multinational epidemiologic study, the prevalence of $\mathrm{PE}$ was similar across countries and age groups (21.0\% in those aged $25-34$ years, $23.6 \%$ in those 35-44 years, and $21.7 \%$ in those $45-54$ years) [27]. Thus, the exact relationship between age and $\mathrm{PE}$ remains unclear due to conflicting study results.

LUTS are generally agreed to be closely associated with erectile dysfunction. Nevertheless, few studies have examined the effect of LUTS on PE. The Epidemiology of LUTS (EpiLUTS) study [4], which consisted of 11,834 men, demonstrated that the presence of terminal dribble, a split stream, incomplete emptying, and bladder area pain were significantly associated with PE (in the EpiLUTS study, the PE question was: "When you have sexual intercourse, how often do you ejaculate before you wanted to?"). However, unlike our study, the EpiLUTS study did not consider IELT in defining $\mathrm{PE}$ and did not exclude patients with a history of using drugs that may influence PE or those who had a history of prostate surgery. Hence, more studies would be needed to identify the exact correlation between LUTS and PE.

While testosterone is known to have a central and peripheral action in the ejaculatory process [28], its association with PE is unclear. An epidemiologic study in 2008 reported that an increase in testosterone is associated with the prevalence of PE [7], but a recent study reported that salivary testosterone is not significantly associated with self-reported IELT [29]. The study also evaluated the association between androgen-related genetic polymorphisms and IELT but did not find a statistically significant association [29]. Such contrasting findings regarding the association between testosterone and PE may be due to the diurnal and day-to-day variation of testosterone. Thus, repeated measurements of testosterone would help to clarify the association between testosterone and $\mathrm{PE}$, but this could not be done in the present study.

Another main limitation of this study is that we diagnosed PE based on a self-reported questionnaire for ejaculatory latency. Self-reported data may be quite different from stopwatch-measured ejaculatory latency. Although we had a relatively large sample size, the prevalence of $\mathrm{PE}$ was relatively low, presumably because the diagnosis was based on a self-reported questionnaire. Despite these limitations, our study is meaningful in that we comprehensively analyzed various factors that are known to play a part in the onset of $\mathrm{PE}$ and verified that MetS is associated with acquired $\mathrm{PE}$ and ejaculatory dysfunction.

\section{CONCLUSIONS}

MetS may be an independent predisposing factor for the development of acquired PE. ORs of MetS were higher than those of NIH-CPSI. Therefore, MetS may be an independent predisposing factor for acquired $\mathrm{PE}$, and the effective prevention and treatment of MetS could also be important for the prevention of acquired $\mathrm{PE}$ or ejaculatory dysfunction. 


\section{Disclosure}

The authors have no potential conflicts of interest to disclose.

\section{Author Contribution}

Research conception and design: Hyun JS, Jeh SU. Data acquisition: Yoon S, Choi JH, Do J, Seo DH, Lee SW, Choi SM. Data analysis and interpretation: Jeh SU, Kang HW. Statistical analysis: Lee C, Kam SC. Drafting of the manuscript: Jeh SU, Hwa JS, Hyun JS. Critical revision of the manuscript: Chung KH, Jeh SU, Hyun JS. Approval of final manuscript: all authors.

\section{REFERENCES}

1. McMahon CG, Lee G, Park JK, Adaikan PG. Premature ejaculation and erectile dysfunction prevalence and attitudes in the Asia-Pacific region. J Sex Medicine 2012;9:454-65.

2. Lee SW, Lee JH, Sung HH, Park HJ, Park JK, Choi SK, et al. The prevalence of premature ejaculation and its clinical characteristics in Korean men according to different definitions. Int J Impot Res 2013;25:12-7.

3. Serefoglu EC, McMahon CG, Waldinger MD, Althof SE, Shindel A, Adaikan G, et al. An evidence-based unified definition of lifelong and acquired premature ejaculation: report of the second International Society for Sexual Medicine ad hoc committee for the definition of premature ejaculation. J Sex Med 2014;11:1423-41.

4. Wein AJ, Coyne KS, Tubaro A, Sexton CC, Kopp ZS, Aiyer LP. The impact of lower urinary tract symptoms on male sexual health: EpiLUTS. BJU Int 2009;103 Suppl 3:33-41.

5. Laumann EO, Nicolosi A, Glasser DB, Paik A, Gingell C, Moreira E, et al.; GSSAB Investigators' Group. Sexual problems among women and men aged 40-80 y: prevalence and correlates identified in the Global Study of Sexual Attitudes and Behaviors. Int J Impot Res 2005;17:39-57.

6. Gonen M, Kalkan M, Cenker A, Ozkardes H. Prevalence of premature ejaculation in Turkish men with chronic pelvic pain syndrome. J Androl 2005;26:601-3.

7. Corona G, Jannini EA, Mannucci E, Fisher AD, Lotti F, Petrone L, et al. Different testosterone levels are associated with ejaculatory dysfunction. J Sex Med 2008;5:1991-8.

8. Sullivan ME, Thompson CS, Dashwood MR, Khan MA, Jeremy JY, Morgan RJ, et al. Nitric oxide and penile erection: is erectile dysfunction another manifestation of vascular disease? Cardiovasc Res 1999;43:658-65.

9. Vallance P, Chan N. Endothelial function and nitric oxide: clinical relevance. Heart 2001;85:342-50.
10. Wheatcroft SB, Williams IL, Shah AM, Kearney MT. Pathophysiological implications of insulin resistance on vascular endothelial function. Diabet Med 2003;20:255-68.

11. Heidler S, Temml C, Broessner C, Mock K, Rauchenwald M, Madersbacher S, et al. Is the metabolic syndrome an independent risk factor for erectile dysfunction? J Urol 2007;177:6514.

12. Skilton MR, Moulin P, Terra JL, Bonnet F. Associations between anxiety, depression, and the metabolic syndrome. Biol Psychiatry 2007;62:1251-7.

13. Pan A, Keum N, Okereke OI, Sun Q, Kivimaki M, Rubin RR, et al. Bidirectional association between depression and metabolic syndrome: a systematic review and meta-analysis of epidemiological studies. Diabetes Care 2012;35:1171-80.

14. Waldinger MD, Berendsen HH, Blok BF, Olivier B, Holstege G. Premature ejaculation and serotonergic antidepressantsinduced delayed ejaculation: the involvement of the serotonergic system. Behav Brain Res 1998;92:111-8.

15. Rosmond R, Bouchard C, Björntorp P. Increased abdominal obesity in subjects with a mutation in the $5-\mathrm{HT}(2 \mathrm{~A})$ receptor gene promoter. Ann N Y Acad Sci 2002;967:571-5.

16. Muldoon MF, Mackey RH, Williams KV, Korytkowski MT, Flory JD, Manuck SB. Low central nervous system serotonergic responsivity is associated with the metabolic syndrome and physical inactivity. J Clin Endocrinol Metab 2004;89:26671.

17. Bolat D, Kocabas GU, Gunlusoy B, Aydogdu O, Aydin ME. The relationship between acquired premature ejaculation and metabolic syndrome: a prospective, comparative study. Int J Impot Res 2017;29:105-9.

18. Grundy SM, Cleeman JI, Daniels SR, Donato KA, Eckel RH, Franklin BA, et al. Diagnosis and management of the metabolic syndrome: an American Heart Association/National Heart, Lung, and Blood Institute scientific statement. Circulation 2005;112:2735-52.

19. World Health Organization. Regional Office for the Western Pacific. The Asia-Pacific perspective: redefining obesity and its treatment. Sydney: Health Communications Australia; 2000;11-2.

20. McMahon CG, Althof SE, Waldinger MD, Porst H, Dean J, Sharlip ID, et al. An evidence-based definition of lifelong premature ejaculation: report of the International Society for Sexual Medicine (ISSM) ad hoc committee for the definition of premature ejaculation. J Sex Med 2008;5:1590-606.

21. Takeuchi T, Nakao M, Nomura K, Yano E. Association of metabolic syndrome with depression and anxiety in Japanese men. Diabetes Metab 2009;35:32-6.

22. Shoelson SE, Herrero L, Naaz A. Obesity, inflammation, and 
insulin resistance. Gastroenterology 2007;132:2169-80.

23. El-Nashaar A, Shamloul R. Antibiotic treatment can delay ejaculation in patients with premature ejaculation and chronic bacterial prostatitis. J Sex Med 2007;4:491-6.

24. McMahon CG, Stuckey BG, Andersen M, Purvis K, Koppiker $\mathrm{N}$, Haughie S, et al. Efficacy of sildenafil citrate (Viagra) in men with premature ejaculation. J Sex Med 2005;2:368-75.

25. Lee WK, Lee SH, Cho ST, Lee YS, Oh CY, Yoo C, et al. Comparison between on-demand dosing of dapoxetine alone and dapoxetine plus mirodenafil in patients with lifelong premature ejaculation: prospective, randomized, double-blind, placebo-controlled, multicenter study. J Sex Med 2013;10:283241.

26. Nicolosi A, Laumann EO, Glasser DB, Moreira ED Jr, Paik A, Gingell C; Global Study of Sexual Attitudes and Behaviors Investigators' Group. Sexual behavior and sexual dysfunctions after age 40: the global study of sexual attitudes and behaviors. Urology 2004;64:991-7.

27. Porst H, Montorsi F, Rosen RC, Gaynor L, Grupe S, Alexander J. The Premature Ejaculation Prevalence and Attitudes (PEPA) survey: prevalence, comorbidities, and professional help-seeking. Eur Urol 2007;51:816-24; discussion 824.

28. Corona G, Rastrelli G, Maggi M. Treatment of premature ejaculation and comorbid endocrine and metabolic disorders. In: Jannini EA, McMahon CG, Waldinger MD, editors. Premature ejaculation: from etiology to diagnosis and treatment. Milano: Springer; 2013;289-303.

29. Jern P, Westberg L, Ankarberg-Lindgren C, Johansson A, Gunst A, Sandnabba NK, et al. Associations between salivary testosterone levels, androgen-related genetic polymorphisms, and self-estimated ejaculation latency time. Sex Med 2014;2:107-14. 